\title{
A Case-Control Study of the Effect of Infant Feeding on Celiac Disease
}

\author{
Ulrike Peters $^{a}$ Sebastian Schneeweiss $^{b, c}$ Elke A. Trautwein ${ }^{a}$ \\ Helmut F. Erbersdobler ${ }^{a}$

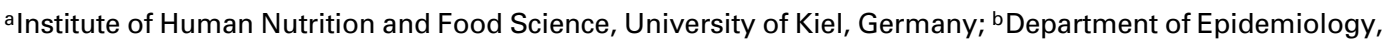 \\ Harvard School of Public Health, Boston, Mass., USA; and 'Department of Medical Informatics, Biometry and \\ Epidemiology, University of Munich, Germany
}

\section{Key Words}

Celiac disease $\cdot$ Infant feeding habits $\cdot$ Breast-feeding • Gluten introduction - Case-control study

\begin{abstract}
Aims: The aim of this study was to investigate the association between the duration of breast-feeding and the age at the first gluten introduction into the infant diet and the incidence and age at onset of celiac disease. Methods: In a case-control study, 143 children with celiac disease and 137 randomly recruited gender- and agematched control children were administered a standardized questionnaire. Multivariate-adjusted odds ratios (OR) as estimates of the relative risk and corresponding 95\% confidence intervals $(95 \% \mathrm{Cl}$ ) were calculated. $\boldsymbol{R e}$ sults: The risk of developing celiac disease decreased significantly by $63 \%$ for children breast-fed for more than 2 months (OR $0.37,95 \% \mathrm{Cl} 0.21-0.64$ ) as compared with children breast-fed for 2 months or less. The age at first gluten introduction had no significant influence on the incidence of celiac disease (OR $0.72,95 \% \mathrm{Cl} 0.29-1.79$ comparing first gluten introduction into infant diet $>3$

U.P. is currently working at the Division of Cancer Epidemiology and Genetics, National Cancer Institute, NIH, Bethesda, Md., USA, and S.S. is currently working at the Division of Pharmacoepidemiology and Pharmacoeconomics, Brigham and Women's Hospital and Harvard Medical School, Boston, Mass., USA.
\end{abstract}

months vs. $\leq 3$ months). Conclusions: A significant protective effect on the incidence of celiac disease was suggested by the duration of breast-feeding (partial breastfeeding as well as exclusive breast-feeding). The data did not support an influence of the age at first dietary gluten exposure on the incidence of celiac disease. However, the age at first gluten exposure appeared to affect the age at onset of symptoms.

Copyright $\odot 2001$ S. Karger AG, Basel

\section{Introduction}

Over the last few decades, several hypotheses have been proposed to explain the pathogenesis of celiac disease. Although a membrane glycoprotein defect, a missing enzyme theory, and a mucosal permeability defect have been implicated, an immunological theory has more recently gained wide acceptance [1]. This theory has proposed that both genetic and environmental factors are involved in the pathogenesis of celiac disease. Environmental factors, such as infant feeding, have been the focus of a number of cross-sectional studies comparing data on infant feeding with the manifestations of celiac disease. Cross-sectional data collected from infants in the general population, and not specifically from infants with celiac disease, showed a correlation between infant feeding habits and celiac disease. These data indicated that with longer duration of breast-feeding and older age at gluten

Prof. Helmut F. Erbersdobler

University of Kiel, Institute of Human Nutrition and Food Science

Düsternbrooker Weg 17, D-24105 Kiel (Germany)

Tel. +49 431597 36780, Fax +49 4315973679

E-Mail erbersdobler@nutrfoodsc.uni-kiel.de 
introduction, the incidence of celiac disease decreased. In addition, the onset of celiac disease was delayed in various populations [2-9]. In Sweden, the incidence of celiac disease has increased during the last decades, particularly in children born after 1982 [10, 11]. Interestingly, during the same time, the infant feeding habits also changed. The gluten content of infant follow-up formulas increased. Further, the Swedish National Health Office recommended a delay in the age of gluten introduction from 4 to 6 months $[12,13]$. In order to investigate why the incidence of celiac disease increased in Sweden, at the same time there was no corresponding increase in neighboring countries, several comparative studies of infant feeding habits were undertaken [12-18]. Data from healthy infants showed that the amount of gluten in the infant diet was higher in Sweden, where the incidence of celiac disease is higher, as compared with its neighboring countries. However, these studies investigated the infant feeding practices of healthy children, and this may not reflect the feeding practices of children with celiac disease.

The following patterns of infant feeding can be listed as potential factors influencing incidence and age at onset of celiac disease: (1) duration of breast-feeding; (2) breastfeeding versus bottle-feeding when gluten is introduced into the diet; (3) age at gluten introduction; (4) amount of gluten in diet, and (5) type of gluten-containing cereals in the diet.

The aim of this case-control study was to analyze the impacts of the duration of breast-feeding (subdivided into partial and exclusive breast-feeding) and the age at gluten introduction on incidence and onset of celiac disease. The results of this study were compared with results from previous observational studies [19-23].

\section{Patients and Methods}

The study design is described in detail elsewhere [24]. The sampling took place from spring 1995 to fall 1996. Celiac disease cases were enrolled from two sources: (1) an incidence study in northern Germany and (2) a biannual meeting of the German Celiac Disease Society (DZG). In the incidence study, all hospitals and pediatricians from the two federal northern states (Schleswig-Holstein and Hamburg) were contacted to identify newly diagnosed patients for the interval 1985-1995 in this region [24]. In Germany, pediatricians have primary responsibility for the majority of preventive tests and services for children. From the patients identified by the incidence study, 74 celiac disease patients were contacted and asked to participate in the case-control study. To obtain a sufficiently large sample, an additional 97 patients were recruited at a nationwide biannual meeting of the DZG. Parents of all recruited children were asked to complete a self-administered standardized questionnaire. If the families did not respond to two reminders, a second questionnaire was mailed to them. Altogether 171 patients were recruited, and 150 $(87.7 \%)$ answered the questionnaire. Patients with incomplete questionnaires or invalidated diagnoses of celiac disease were excluded which reduced the number of cases to $143(83.6 \%)$. The parents of the patients were asked about the diagnosis of celiac disease. Additional diagnostic information (e.g., biopsy protocols, symptoms, diagnostic test) for the case group that was enrolled in the incidence study was provided from the patient's primary pediatrician. This information was used to validate the diagnosis of celiac disease.

Of all 143 patients, $133(93 \%)$ had at least one biopsy of specimen of the small intestine with findings typical of celiac disease according to the criteria of the European Society for Pediatric Gastroenterology and Nutrition [25]. The remaining $10(7 \%)$ patients had strong clinical and immunological findings consistent with celiac disease. These 10 patients had typical symptoms of celiac disease which disappeared after the introduction of a gluten-free diet. Reasons for missing or invalid biopsy results included parents' refusal to obtain a biopsy specimen, introduction of gluten-free diet prior to biopsy, and unsuccessful biopsy. Ninety-eight percent of the patients showed typical symptoms of the disease during the diagnosis. These patients were classified as symptomatic celiac disease patients. All 143 patients responded symptomatically to a gluten-free diet. Characteristics of the two case groups (incidence study from northern Germany and meeting of the DZG) were compared before pooling. No significant differences were observed between the two groups.

A gender- and age-matched random group of 261 control children was identified through the population registry of the two federal states Hamburg and Schleswig-Holstein. The same standardized questionnaire used for the celiac disease patients (with exclusion of questions about diagnosis of celiac disease) was sent to the families. A follow-up protocol identical to that of the case group was used to remind families that did not respond. One hundred and forty-three (54.8\%) parents answered the questionnaire. Children were excluded from the control group, if the child of a first-order relative had celiac disease or dermatitis herpetiformis $(\mathrm{n}=3)$ or if the questionnaire was incomplete $(\mathrm{n}=$ $3)$. One hundred and thirty-seven controls (52.5\%) were eligible for the analysis. Enrollment for the case and control groups was limited to children younger than 10 years. All parents of children in the study were informed about nature and purpose of the study, data protection, and data deletion. Further, participants were informed that participation was voluntary and could be withdrawn at any time. The Commissioner of Data Protection oversaw the sampling.

All parents were asked about duration of breast-feeding (exclusive and partial) and the type of bottle-feeding. The age of the child when gluten-containing products were introduced was assessed separately for various infant products such as porridge, cereal drinks, multigrain and oat flakes, bread, and cakes. Parents of children with celiac disease were also asked about diagnosis and symptoms.

\section{Statistical Analysis}

Comparisons between the two case groups were performed before pooling; $t$ tests, Mann-Whitney U tests, and Pearson chi-square-tests were used, depending on the characteristics of the variables. Differences were reported as significantly different, if double-sided $p$ values were $<0.05$. An unmatched analysis of the case-control study was performed, because matched and unmatched odds ratios (ORs) for the main effects did not differ. ORs as relative risk estimates and the corresponding $95 \%$ confidence intervals (CI) were estimated by fitting multiple logistic regression models to the data. The following potential confounders were taken into account: age, sex, number of 


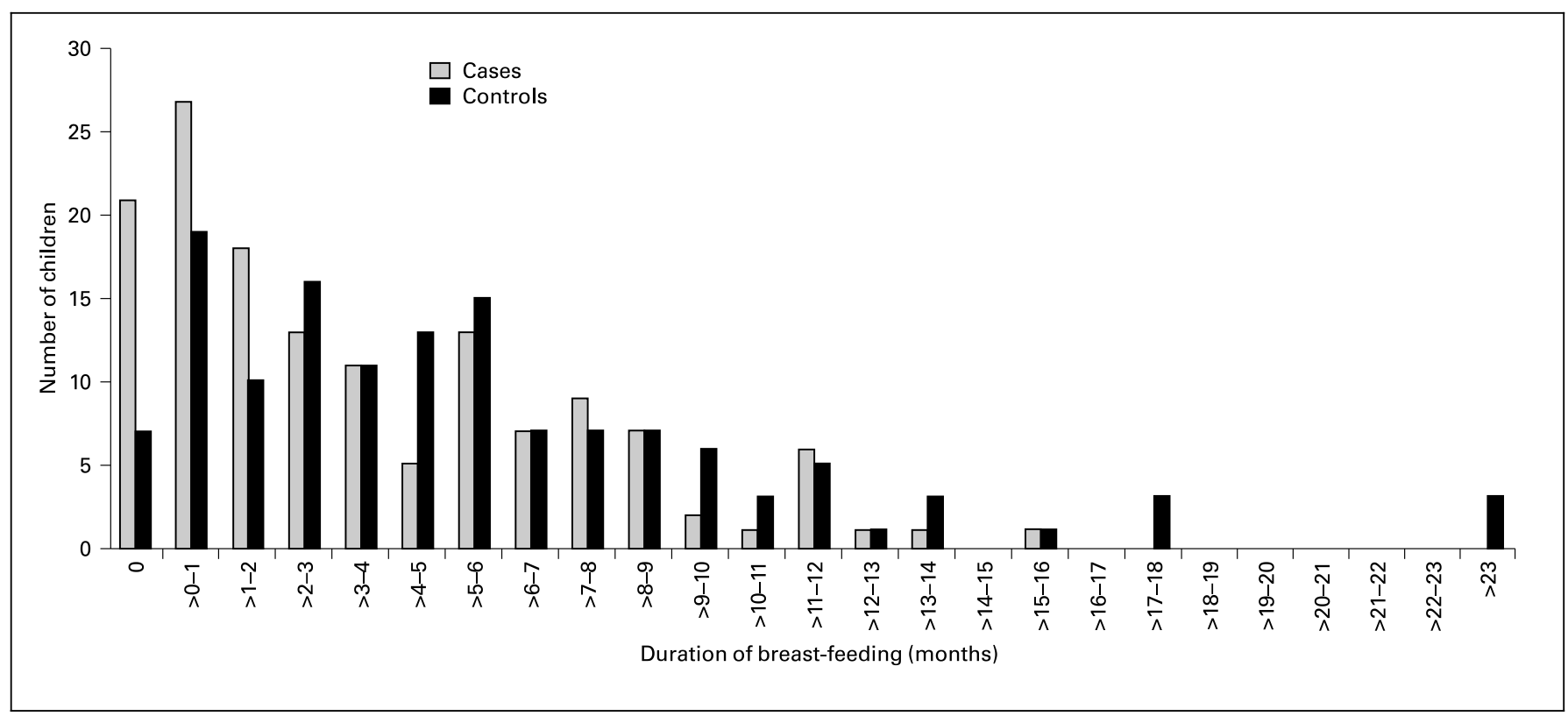

Fig. 1. Duration of breast-feeding in children with celiac disease $(n=143)$ and in control children $(n=137)$.

Table 1. Characteristics of infant feeding in cases with celiac disease and population-based controls

\begin{tabular}{|c|c|c|c|c|c|c|c|}
\hline \multirow[t]{2}{*}{ Infant feeding characteristics } & \multicolumn{3}{|c|}{ Cases } & \multicolumn{3}{|c|}{ Controls } & \\
\hline & $\mathrm{n}$ & mean & SD & $\mathrm{n}$ & mean & SD & \\
\hline \multicolumn{8}{|l|}{ Breast-feeding, months } \\
\hline Partially & 143 & 3.9 & 3.8 & 137 & 5.9 & 5.4 & $\mathrm{p}<0.01$ \\
\hline Exclusively & 143 & 2.1 & 2.5 & 137 & 2.7 & 2.3 & $\mathrm{p}<0.01$ \\
\hline Age at gluten introduction, months & 134 & 5.4 & 1.6 & 136 & 5.7 & 2.5 & NS \\
\hline Breast-fed when gluten introduced, $\%$ & 134 & 33 & & 136 & 51 & & $\begin{array}{l}\text { OR } 0.47 \\
\text { CI } 0.29-0.7\end{array}$ \\
\hline
\end{tabular}

Statistical comparisons were performed using Wilcoxon's test.

inhabitants of residence, family predisposition to celiac disease, and duration of breast-feeding or age at gluten introduction. The likelihood ratio test and the Hosmer-Lemeshow goodness of fit test were used to test the model fit [26]. Interactions were tested by Wald test of product term at a $\mathrm{p}$ value of 0.2 . In the case group, mean and median ages at onset of symptoms were compared with age at gluten introduction (comparing $>4$ months to $\leq 4$ months) and duration of breast-feeding (comparing $>2$ months to $\leq 2$ months) by log-rank tests. Cumulative proportions of age at onset of symptoms were estimated by the product-limit method and displaced as Kaplan-Meier plots [27]. The effects of duration of breast-feeding and age at gluten introduction on the age of onset of symptoms were estimated simultaneously by fitting a multiple Cox regression model [27] adjusted for age, sex, number of inhabitants of residence, and family predisposition to celiac disease.

A Case-Control Study of the Effect of Infant Feeding on Celiac Disease

\section{Results}

The mean age of cases and controls at enrollment was 6.4 (median 6.2) years. The mean duration of breast-feeding (partial and exclusive) was 3.9 (range 0.0-15.5) months in cases and 5.9 (range 0.0-36.0) months in controls (table 1, fig. 1). The mean age at first exposure to foods containing gluten was in cases 5.4 (range 2.0-12.0) months and in controls 5.7 (range 1.0-12.0) months (table 1, fig. 2). As compared with the control group, the children with celiac disease were breast-fed (partially and exclusively) for a significantly shorter period (table 1). The age at gluten introduction did not differ significantly

Ann Nutr Metab 2001;45:135-142 
Fig. 2. Age at first dietary gluten exposure in cases with celiac disease $(n=134)$ and controls $(\mathrm{n}=136)$.

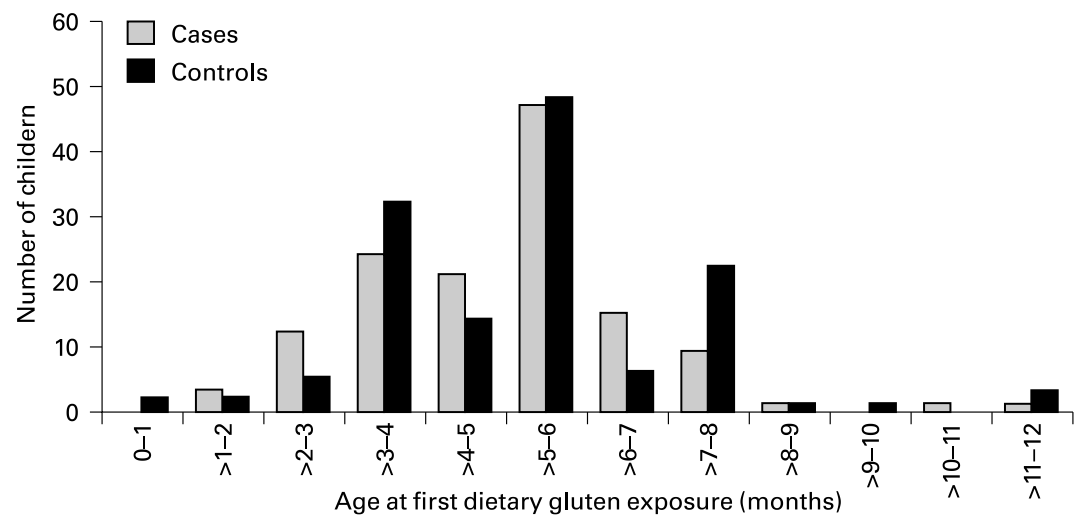

Table 2. Association of celiac disease and duration of breast-feeding in a case control study

\begin{tabular}{lll}
\hline Duration of breast-feeding & OR $^{\mathrm{a}}$ & $95 \%$ CI of OR \\
\hline Per month (continuous) & 0.89 & $0.84-0.95$ \\
$>2$ months vs. $\leq 2$ months & 0.37 & $0.21-0.64$ \\
0 month & 1.00 & - \\
$>0$ to $<3$ months & 0.39 & $0.15-1.02$ \\
$\geq 3$ to $<7$ months & 0.22 & $0.08-0.59$ \\
$\geq 7$ months & 0.18 & $0.06-0.52$
\end{tabular}

a Adjusted for age, sex, number of inhabitants of residence, family history of celiac disease, and age at gluten introduction.

between children with celiac disease and control children. As compared with controls, cases were 53\% less likely to be breast-fed, when gluten was introduced into their diet (OR 0.47, 95\% CI 0.27-0.84).

The risk of developing celiac disease decreased significantly by $63 \%$ for children being breast-fed for more than 2 months (OR 0.37, 95\% CI 0.21-0.64) as compared with children being breast-fed for 2 months or less (table 2). Furthermore, the risk of celiac disease, as compared with children who were not breast-fed, decreased by about $61 \%$ in children who were breast-fed for $>0$ to $<3$ months, by about $78 \%$ in children who were breast-fed for $\geq 3$ to $<7$ months, and by about $82 \%$ in children who were breastfed for 7 months or more (table 2). Coding the duration of breast-feeding continuously indicated a significant reduction of the risk by $11 \%$ (OR $0.89,95 \%$ CI $0.84-0.95)$ for each month of breast-feeding (table 2). Considering only the period during which the children were breast-fed
Table 3. Relative risk of celiac disease by different categories of age at gluten introduction

\begin{tabular}{lll}
\hline Age at gluten introduction & OR $^{\mathrm{a}}$ & $95 \% \mathrm{CI}$ of OR \\
\hline Per month (continuous) & 0.98 & $0.86-1.11$ \\
$>3$ months vs. $\leq 3$ months & 0.72 & $0.29-1.79$ \\
$\leq 3$ months & 1.00 & - \\
$>3$ to $\leq 4$ months & 0.52 & $0.18-1.44$ \\
$>4$ to $\leq 5$ months & 1.21 & $0.40-3.68$ \\
$>5$ months & 0.72 & $0.28-1.85$ \\
\hline
\end{tabular}

a Adjusted for age, sex, number of inhabitants of residence, family history of celiac disease, and duration of breast-feeding.

exclusively, the risk was reduced by $12 \%$ (OR $0.88,95 \%$ CI 0.79-0.98) for each nursed month. As compared with children who were not breast-fed $(n=26)$, the OR of celiac disease decreased slightly for each successive month of breast-feeding (partially breast-fed: fig. 3; exclusively breast-fed: fig. 4).

The age at first gluten introduction into the diet did not indicate a significant association with the incidence of celiac disease (OR 0.72, 95\% CI 0.29-1.79 comparing first gluten introduction into infant diet $>3$ months, vs. $\leq 3$ months; table 3 ).

Neither the age at dietary gluten introduction nor the family predisposition to celiac disease showed a relationship to the duration of breast-feeding.

Likelihood ratio test and Hosmer-Lemeshow goodness of fit test showed that the logistic regression model fits the data well. Depending on the final model, the $p$ values of the likelihood ratio tests were between 0.0002 and 0.0000 


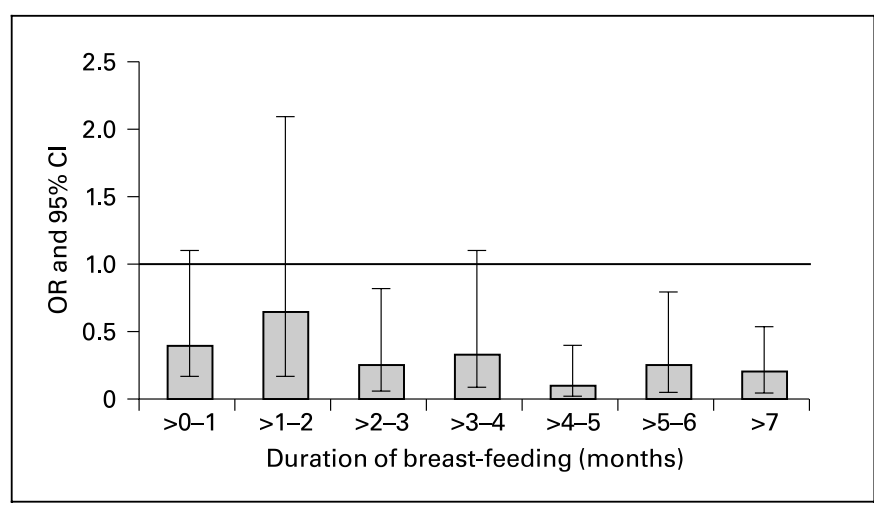

Fig. 3. Association of celiac disease and duration of partial breastfeeding (reference group: never breast-fed children, $n=26$ ), $\mathrm{p}$ for trend $<0.001$

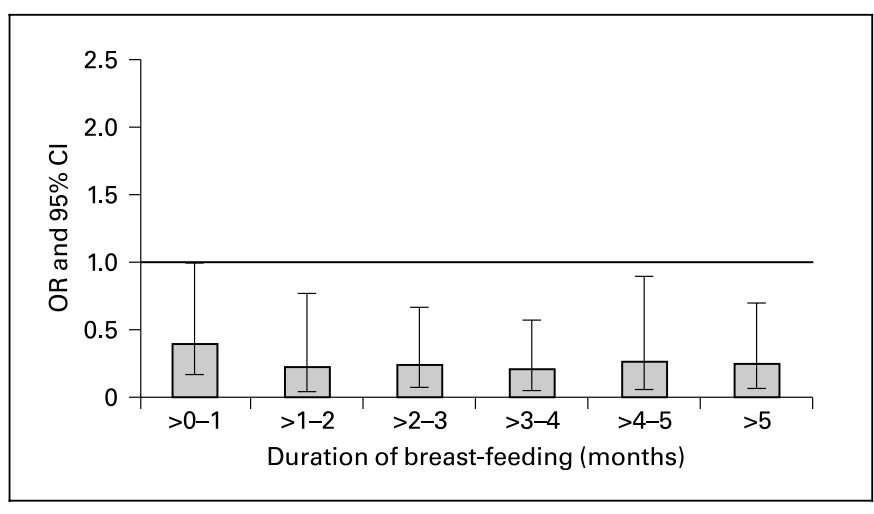

Fig. 4. Association of celiac disease and duration of exclusively breast-feeding (reference group: never breast-fed children, $n=26$ ), $\mathrm{p}$ for trend $<0.05$.

Table 4. Age at onset of symptoms of celiac disease stratified by infant feeding characteristics

\begin{tabular}{|c|c|c|c|c|c|c|}
\hline \multirow[t]{2}{*}{ Infant feeding } & \multicolumn{4}{|c|}{ Age at onset of symptoms, months } & \multirow[t]{2}{*}{$\mathrm{n}$} & \\
\hline & mean & $95 \% \mathrm{CI}$ & median & $95 \% \mathrm{CI}$ & & \\
\hline \multicolumn{7}{|c|}{ Breast-feeding (partial) } \\
\hline$\leq 2$ months & 11 & 9,12 & 9 & 8,10 & 60 & \multirow{2}{*}{$\mathrm{p}<0.01$} \\
\hline$>2$ months & 15 & 12,18 & 11 & 9,13 & 75 & \\
\hline \multicolumn{7}{|c|}{ Age at gluten introduction } \\
\hline$\leq 4$ months & 9 & 7,12 & 8 & 6,10 & 38 & \multirow{2}{*}{$\mathrm{p}<0.01$} \\
\hline$>4$ months & 14 & 12,17 & 11 & 10,12 & 90 & \\
\hline
\end{tabular}

Statistical comparisons were performed using log-rank test.

as compared with the simplest model (Hosmer-Lemeshow test: $p$ value between 0.12 and 0.84 ).

Data for the age at onset of symptoms were available for 135 of the 143 celiac disease patients. The median age at onset of symptoms was 13.0 (range 1.0-84.0) months. The data showed that symptoms of celiac disease in patients who were not breast-fed or breast-fed for 2 months or less appeared on average 4 months earlier than in patients who were breast-fed for more than 2 months ( $p<0.01$; table 4$)$. For the age at gluten introduction, a significant difference in the onset of symptoms was observed as well. The onset of symptoms was on average 5 months earlier when gluten was introduced early (comparing $>4$ months vs. $\leq 4$ months, $p<0.01$; table 4 ). Figures 5 and 6 show the increasing cumulative probability of onset of symptoms of celiac disease with increasing age, depending on different durations of breast-feeding and age at gluten introduction. When both predictors, dura- tion of breast-feeding and age at gluten introduction, were modeled simultaneously, only the duration of breast-feeding was a significant predictor in a Cox regression analysis adjusted for age, sex, number of inhabitants of residence, and family predisposition to celiac disease. The relative risk for breast-feeding comparing $>2$ months to $\leq 2$ months was 0.64 (95\% CI 0.43-0.95), and the relative risk for age at gluten introduction (comparing $>4$ months to $\leq 4$ months) was 0.66 (95\% CI 0.44-1.00).

\section{Discussion}

The results of this case-control study suggest that children who were breast-fed for more than 2 months have a $63 \%$ reduced risk of developing celiac disease as compared with their peers who were breast-fed for 2 months or less. The inverse association between breast-feeding 


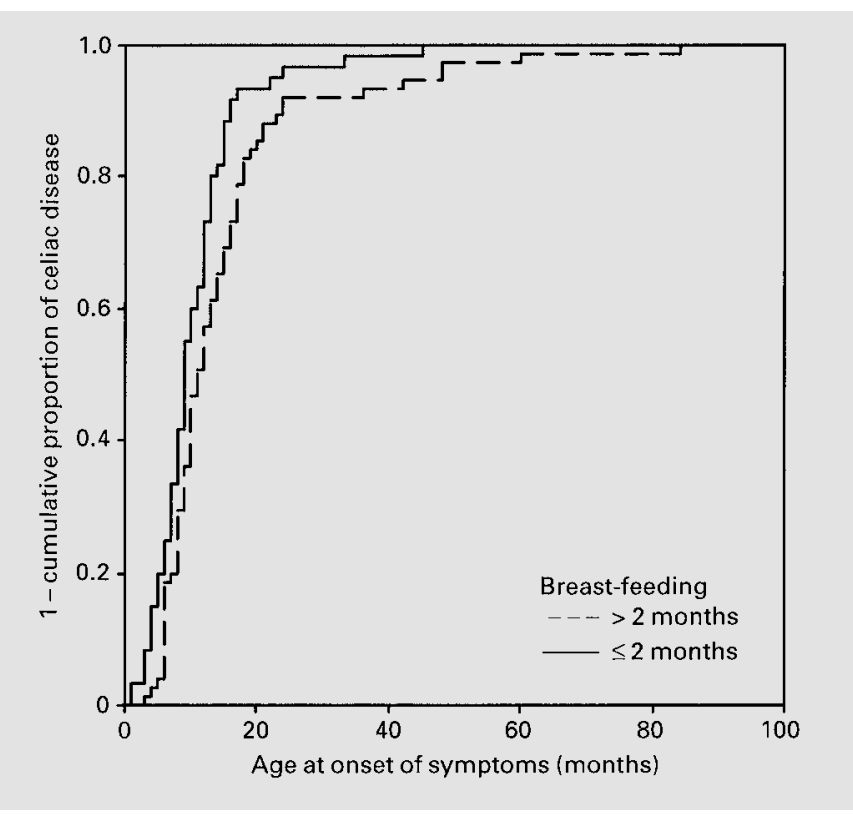

Fig. 5. Kaplan-Meier plots of age at onset of symptoms of celiac disease stratified by duration of breast-feeding $(p=0.006$; log-rank test).

and celiac disease was seen for exclusive breast-feeding and partial breast-feeding. The data also suggest a trend of an increasing protective effect with increasing duration of breast-feeding.

Further, the data suggest that for the children with celiac disease, the age at onset of symptoms was significantly higher in those who were breast-fed longer and were exposed to gluten at a later age. Adjustments for gender, number of inhabitants in the residence, prior cases in the family, and age at gluten introduction resulted in a smaller but still significant effect of the duration of breastfeeding. The duration of breast-feeding had a stronger effect on the age at onset as compared with the age at introduction of gluten. However, assuming that a later onset is not related to a delayed diagnosis, it is unclear whether an average delay in symptoms of 4 months is clinically relevant, given that the children will still develop the disease. A positive effect of breast-feeding on the onset of celiac disease was observed in some earlier studies [7, 28-32]. However, these studies did not adjust for potential confounders which were shown in our study to bias results for the age at introduction of gluten. Only the studies performed by Greco et al. [29] and Anderson and Brueton [33] investigated simultaneously age at gluten introduction and duration of breast-feeding. Greco et al.

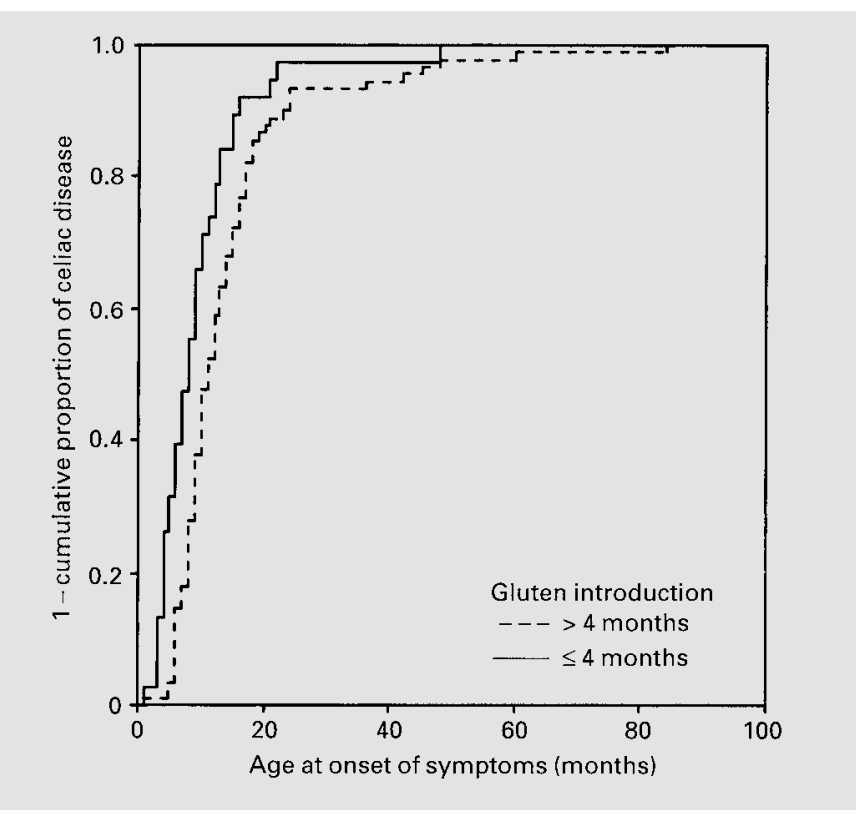

Fig. 6. Kaplan-Meier plots of age at onset of symptoms of celiac disease stratified by age at first gluten introduction $(p=0.002$; log-rank test).

[29] described a positive effect of breast-feeding, while Anderson and Brueton [33] found a positive effect for the age at gluten introduction on the onset of celiac disease.

A general limitation of our study design was the difficulty in distinguishing between the effect of breast-feeding and the start of gluten substitution, since they showed considerable correlation $(r=0.44$ and $r=0.54)$ in the two case subgroups. Mothers who breast-feed their child exclusively will typically not start feeding gluten before they switch at least to partial breast-feeding. Since the effect of age at first exposure to gluten was weaker and not statistically significant, our data suggest that the protective effect of breast-feeding was more important than the effect of later gluten introduction. This was shown only in a population of children up to 10 years of age and may reverse at a later age.

Case-control studies are an efficient design for rare diseases, but methodological limitations must be considered. The response rate was high in the case group (88\%), but significantly lower in the control group (55\%). Although a control response rate of $55 \%$ is typical of mailed questionnaires in Germany, it cannot be ruled out that a selected group of control parents responded. A likely scenario is that parents with a greater interest in nutrition and infant feeding and higher socioeconomic status are more likely 
both to participate in the study and to nurse their children for a longer duration. This would bias the effect of breastfeeding towards a stronger protective effect (away from the null).

Due to the retrospective design, misclassification of the duration of breast-feeding and of the age at introduction of gluten as well as misclassification of the age at onset of symptoms were likely to occur. A populationbased case-control study compares the exposure distribution of the source population in randomly selected controls with the exposure of the cases arising from the source population [34]. However, in our study, only 67 cases were identified in the incidence study and fulfilled the criteria of a population-based study design. Subsequently, 76 cases were enrolled at the national meeting of the DZG. Both subgroups of cases did not differ in measured characteristics, and we combined these two case groups in the analysis. Selection bias is possible because we cannot rule out the chance that patients from the DZG meeting differ with regard to the socioeconomic status.

The effect of infant feeding on celiac disease has been investigated in five case-control studies [19-23] and in our study. A protective effect of breast-feeding on the development of celiac disease was suggested in all studies, except the study of Ascher et al. [23]. An effect for the age at gluten introduction on the incidence of celiac disease was found only in the study of Ivarsson et al. [22]. The age of the children at the time of the interview differed among studies. In the study of Ascher et al. [23], the median age for the cases was 7.9 years and for the controls 7.4 years. In our study, the median age was also high: 6.2 (mean 6.4) years. More precise data about infant feeding can be reported by Fälth-Magnusson [21] (mean age 3.1 years) and Greco et al. [20] (mean age 2.3 years), because the interview time was closer to the time period of interest.

The methods of statistical analyses also varied among the studies. Fälth-Magnusson et al. [21] and Ascher et al. [23] used descriptive statistics. The study of Ivarsson et al. [22] was published only in abstract form, and thus data about the statistical analyses are not available. Only the studies of Auricchio et al. [19] and Greco et al. [20] controlled for potential confounders by matching or stratified analyses. Auricchio et al. [19] used siblings as controls. However, since similar infant feeding patterns can be expected among siblings, overmatching has to be considered in the study of Auricchio et al. [19].

All case-control studies other than the study of Ascher et al. [23] showed a protective effect of breast-feeding. Our study as well as the study performed by Fälth-Magnusson et al. [21] found a significantly protective effect on the incidence of celiac disease for the duration of partial breast-feeding as well as exclusive breast-feeding. This result may demonstrate a protective effect of breast-feeding in general. Ascher et al. [23] investigated only genetically predisposed siblings of patients with celiac disease. A biopsy of the small intestine performed on all siblings showed that 8 out of 81 biopsied children had a silent celiac disease. These 8 silent patients formed the case group. These cases were 'more or less' asymptomatic cases [23], while the cases in the other studies were clinically diagnosed and, therefore, mainly symptomatic cases. Apart from problems with the study design, which included a relatively old age of the children and a low sample size of only 8 cases, the lack of symptomatic cases could explain why Ascher et al. [23] reported no effect of the duration of breast-feeding. Asymptomatic cases are underdiagnosed, and data on infant feeding habits of asymptomatic children with celiac disease are rare. The duration of breast-feeding of 2 asymptomatic cases in our study was 12 months. The duration of these 2 cases was 8.1 months longer than the average duration of breastfeeding in all cases. Because of the small sample size of asymptomatic cases, the data are inconclusive, yet can generate the hypothesis that a long duration of breastfeeding reduces symptoms and delays the onset of celiac disease. Further research on infant feeding of cases with asymptomatic celiac disease is necessary.

Ivarsson et al. [22] reported an effect of age at gluten introduction on celiac disease; however, the effect was inconsistent. The risk of celiac disease increased when gluten was introduced late [22]. All other case-control studies including the present one did not find a significant association between the age at first exposure to gluten with celiac disease [19-21, 23]. It is possible that parents had greater difficulty remembering at what time they first fed their children food containing gluten than remembering if and how long the children were breast-fed. Misclassification may explain why the studies did not find an association between age at gluten introduction and celiac disease. It has been previously proposed that an abrupt introduction of a high amount of gluten in infant feeding has an effect on celiac disease [12-18]. However, the quantitative effect of gluten could not be investigated with our retrospective study design. A longitudinal study with prospective measures of dietary intake of gluten would be a more suitable study design for this purpose. But because of the low incidence rate of celiac disease, a very large sample size would be needed for a prospective study. Therefore, a prospective cohort is a less realistic study design. 
In summary, the results of this case-control study suggest a protective effect for partial and exclusive breastfeeding on the incidence of celiac disease. Breast-feeding also appears to delay the onset of symptoms in children. The effect of age at first gluten exposure on the onset of symptoms appears to be weaker.

\section{Acknowledgments}

We thank Hammermühle GmbH, Maikammer, Germany, and the DZG for their financial and technical support. We also thank the patients and physicians for participating in the study.

\section{References}

1 Mäki M, Collin P: Coeliac disease. Lancet 1997;349:1755-1759.

2 Littlewood JM, Crollick AJ, Richards IDG: Childhood coeliac disease is disappearing. Lancet 1980;ii:1359.

3 Challacombe DN, Baylis JM: Childhood coeliac disease is disappearing. Lancet 1980;ii: 1360.

4 Dossetor JFB, Gibson AAM, McNeish AS: A recent reduction in the incidence of childhood coeliac disease in the West of Scotland; in McConnell RB (ed): The Genetics of Coeliac Disease. Lancaster, MPT Press, 1981, pp 4145.

5 Similä S, Kokkonen J, Voulukka P, Kouvalainen K: Childhood coeliac disease. Lancet 1981; ii:494-495.

6 Stevens FM, Egan-Mitchell B, Cryan E, McCarthy CF, McNicholl B: Decreasing incidence of coeliac disease. Arch Dis Child 1987; 62:465-468

7 Mäki M, Kallonen K, Lähdeaho M-L, Visakorpi JK: Changing pattern of childhood coeliac disease in Finland. Acta Paediatr Scand 1988; 77:408-412.

8 Greco L, Tozzi AE, Mayer M, Grimaldi M, Silano G, Auricchio S: Unchanging clinical picture of coeliac disease presentation in Campania, Italy. Eur J Pediatr 1989;148:610-613.

9 Mäki M, Holm K: Incidence and prevalence of coeliac disease in Tampere: Coeliac disease is not disappearing. Acta Paediatr Scand 1990; 79:980-982.

10 Lindberg T: Coeliac disease and infant feeding practices. Lancet 1981;i:449.

11 Ascher H, Krantz I, Kristiansson B: Increasing incidence of coeliac disease in Sweden. Arch Dis Child 1991;66:608-611.

12 Kristiansson B, Ascher H, Odenman I, Sandberg L: The incidence of coeliac disease and changes in gluten consumption; in Mearin ML, Mulder CJJ (eds): Development in Gastroenterology: Coeliac Disease. 40 Years GlutenFree. Dordrecht, Kluwer, 1991, pp 107-114.
13 Cavell B, Stenhammar L, Ascher H, Danielsson L, Dannaeus A, Lindberg T, Lindquist B: Increasing incidence of childhood coeliac disease in Sweden: Results of a national study. Acta Paediatr 1992;81:589-592.

14 Mäki M, Holm K, Ascher H, Greco L: Factors affecting clinical presentation of coeliac disease: Role of type and amount of gluten-containing cereals in the diet; in Auricchio S, Visakorpi JK (eds): Common Food Intolerances. 1. Epidemiology of Coeliac Disease. Dyn Nutr Res. Basel, Karger, 1992, vol 2, pp 25-44.

15 Ascher H, Holm K, Kristiansson B, Mäki M: Different features of coeliac disease in two neighbouring countries. Arch Dis Child 1993; 69:375-380.

16 Michaelsen KF, Weile B, Larsen P, Samuelson G, Krasilnikoff PA: Does the low intake of wheat in Danish infants cause the low incidence rate of coeliac disease? Acta Paediatr 1993;82:605-606.

17 Weile B, Cavall B, Nivenius K, Krasilnikoff PA: Striking differences in the incidence of childhood celiac disease between Denmark and Sweden: A plausible explanation. J Pediatr Gastroenterol Nutr 1995;21:64-68.

18 Mitt K, Uibo O: Low cereal intake in Estonian infants: The possible explanation for the low frequency of coeliac disease in Estonia. Eur $\mathbf{J}$ Clin Nutr 1998;52:85-88.

19 Auricchio S, Follo D, de Ritis G, et al: Does breast-feeding protect against the development of clinical symptoms of celiac disease in children? J Pediatr Gastroenterol Nutr 1983;2: 428-433.

20 Greco L, Auricchio S, Mayer M, Grimaldi M: Case-control study on nutritional risk factors in celiac disease. J Pediatr Grastroenterol Nutr 1988;7:395-399.

21 Fälth-Magnusson K, Franzen L, Jansson G, Laurin P, Stenhammar L: Infant feeding history shows differences between Swedish celiac and reference children. Pediatr Allergy Immunol 1996;7:1-5.

22 Ivarsson A, Persson LA, Hernell O: Coeliac disease has a multifactorial ethiology (abstract). 7th Int Symp on Coeliac Disease, Tampere 1996.
23 Ascher H, Krantz I, Rydberg L, Nordin P, Kristiansson B: Influence of infant feeding and gluten intake on coeliac disease. Arch Dis Child 1997;76:113-117.

24 Peters U: Epidemiologische Studien zur Zöliakie: Inzidenz in Norddeutschland 1985 bis 1994 sowie eine Fall-Kontroll-Studie zum Einfluss der Säuglingsernährung auf die Entstehung der Zöliakie und zum Auftreten assoziierter Erkrankungen; Dissertation Universität Kiel, 1998.

25 Walker-Smith JA, Guandalini S, Schmitz J, Shmerling DH, Visakorpi JK: Revised criteria for diagnosis of coeliac disease. Arch Dis Child 1990;65:909-911.

26 Hosmer DW, Lemeshow S: Applied Logistic Regression. New York, Wiley, 1989.

27 Harris EK, Albert A: Survivorship Analysis for Clinical Studies. New York, Dekker, 1991.

28 McNeish AS, Anderson CM: Coeliac disease: The disorder in childhood. Clin Gastroenterol 1974;3:127-144.

29 Greco L, Mayer M, Grimaldi M, Follo D, De Ritis G, Auricchio S: The effect of early feeding on the onset of symptoms in celiac disease. J Pediatr Gastroenterol Nutr 1985;4:52-55.

30 Kelley DA, Phillips AD, Elliott EJ, Dias JA, Walker-Smith JA: Rise and fall of coeliac disease 1960-1985. Arch Dis Child 1989;64: 1157-1160.

31 Ansaldi N, Tavassoli K, Dell'Olio D, Bramante L, Faussone D, Balocco L, Oderda G: Clinical data on celiac disease with an early or late onset (abstract). Minerva Pediatr 1991;43:377-381.

32 Rawashdeh MO, Khalil B, Raweily E: Celiac disease in Arabs. J Pediatr Gastroenterol Nutr 1996;23:415-418.

33 Anderson CM, Brueton MJ: Does breast-feeding protect against the development of clinical symptoms of celiac disease in children? J Pediatr Gastroenterol Nutr 1985;4:507.

34 Wacholder S, McLaughlin JK, Silverman DT, Mandel JS: Selection of controls in case-control studies. I. Principles. Am J Epidemiol 1992; 135:1019-1028. 